\title{
IRMPD spectroscopy sheds new (InfraRed) light on the sulfate pattern of carbohydrates
}

DOI:

10.1021/acs.jpca.6b11642

\section{Document Version}

Accepted author manuscript

Link to publication record in Manchester Research Explorer

\section{Citation for published version (APA):}

Schindler, B., Barnes, L., Gray, J. C., Chambert, S., Flitsch, S., Oomens, J., Daniel, R., Allouche, A. R., \& Compagnon, I. (2017). IRMPD spectroscopy sheds new (InfraRed) light on the sulfate pattern of carbohydrates. Journal of Physical Chemistry A, 121. https://doi.org/10.1021/acs.jpca.6b11642

\section{Published in:}

Journal of Physical Chemistry A

\section{Citing this paper}

Please note that where the full-text provided on Manchester Research Explorer is the Author Accepted Manuscript or Proof version this may differ from the final Published version. If citing, it is advised that you check and use the publisher's definitive version.

\section{General rights}

Copyright and moral rights for the publications made accessible in the Research Explorer are retained by the authors and/or other copyright owners and it is a condition of accessing publications that users recognise and abide by the legal requirements associated with these rights.

\section{Takedown policy}

If you believe that this document breaches copyright please refer to the University of Manchester's Takedown Procedures [http://man.ac.uk/04Y6Bo] or contact uml.scholarlycommunications@manchester.ac.uk providing relevant details, so we can investigate your claim.

\section{OPEN ACCESS}




\title{
IRMPD spectroscopy sheds new (InfraRed) light on the sulfate pattern of carbohydrates
}

B. Schindler, ${ }^{\dagger}$ L. Barnes, ${ }^{\dagger}$ C. J. Gray, ${ }^{\ddagger}$ S. Chambert, ${ }^{\S}$ S. L. Flitsch, ${ }^{\ddagger}$ J. Oomens,,${ }^{\Uparrow \bullet}$ R. Daniel, ${ }^{* \#}$ A.R. Allouche $^{\dagger}$ and I. Compagnon ${ }^{* a}$

${ }^{\dagger}$ Univ Lyon, Université Claude Bernard Lyon 1, CNRS, Institut Lumière Matière, F-69622, VILLEURBANNE, France.

${ }^{\ddagger}$ School of Chemistry \& Manchester Institute of Biotechnology, The University of Manchester, 131 Princess Street, Manchester, M1 7 DN, United Kingdom

${ }^{\S}$ Univ Lyon, INSA-Lyon, CNRS, Université Lyon 1, CPE Lyon, ICBMS, UMR 5246, Bâtiment Jules Verne, 20 avenue Albert Einstein, F-69621 Villeurbanne, France

『 Radboud University, Institute for Molecules and Materials, FELIX Laboratory, Toernooiveld 7, 6525ED Nijmegen, The Netherlands

$\checkmark$ Van't Hoff Institute for Molecular Sciences, University of Amsterdam, Science Park 904, 1098XH Amsterdam, The Netherlands

\# LAMBE UMR 8587 CNRS, Laboratoire Analyse et Modélisation pour la Biologie et l'Environnement, Université d'Evry Val d'Essonne, 91025 Evry, France

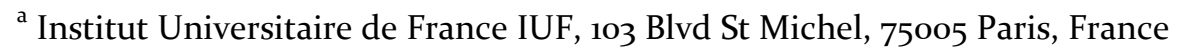

\begin{abstract}
IR spectroscopy of gas phase ions is proposed to resolve positional isomers of sulfated carbohydrates. Mass spectrometric fingerprints and gas phase vibrational spectra in the near and mid IR regions were obtained for sulfated monosaccharides, yielding unambiguous signatures of sulfated isomers. We report the first systematic exploration of the biologically relevant but notoriously challenging deprotonated state in the near IR region. Remarkably, anions displayed very atypical vibrational profiles, which challenge the well-established DFT (Density Functionnal Theory) modeling. The proposed approach was used to elucidate the sulfate patterns in glycosaminoglycans - a ubiquitous class of mammalian carbohydrates - which is regarded as a major challenge in carbohydrate structural analysis. Isomeric glycosaminoglycan disaccharide from heparin and chondroitin sources where resolved, highlighting the potential of InfraRed Multiple Photon Dissociation spectroscopy as a novel structural tool for carbohydrates.
\end{abstract}

\section{INTRODUCTION}

The analysis of the glycome, covering the entire repertoire of carbohydrate structures produced by cells, attracts growing attention. ${ }^{1,2} \mathrm{~A}$ major challenge in the characterization of glycosidic chains is the versatility of structures as a consequence of dynamic modifications as well as of their non-gene driven nature. In this field, mass spectrometry (MS) has become a primary technique for characterization, especially when only small quantities or complex samples are available. However, application of MS in glycomics is also notorious for ambiguities raised by the large numbers of isomers, as the carbohydrate building blocks can differ only by the stereochemistry of a carbon atom. Other key isomeric features making structural elucidation by MS difficult include (i) the regiochemistry of the glycosidic bond linking two carbohydrate moieties; (ii) the anomer stereochemistry ( $\alpha$ or $\beta$ ); (iii) possible epimerization; (iv) the structure of the monomeric ring $(\mathrm{v})$ the identification of the position of commonly observed modifications such as sulfation.

The elucidation of sulfate patterns is regarded as a major challenge in carbohydrate analysis, and in particular in the case of glycosaminoglycans (GAGs). This major class of bioactive sulfated carbohydrates illustrates the biological significance of sulfation, for example in the case of the fine tuning of the protein binding properties of heparin (Hp)/heparan sulfate (HS). ${ }^{3}$ On the one hand, the 3-O-sulfation site was found to be crucial for the blood anticoagulant activity of heparin ${ }^{4}$ and on the other hand, the more common 6-O-sulfation pattern on HS was found to be responsible for controlling cell proliferation., ${ }^{5,6}$

In this context, continuous efforts are made to develop MS strategies for obtaining structural information on carbohydrate structures, usually involving 
chromatographic or electrophoretic separation associated or not with chemical derivation, gas phase reactivity with metals, ion mobility spectrometry, or fragmentation modes alternative to collision induced dissociation (CID), such as electron detachment dissociation (EDD) and InfraRed Multiple Photon Dissociation (IRMPD). ${ }^{7-14}$ On the other hand, spectroscopic approaches provide direct and refined structural information but are generally technically incompatible with mass spectrometry. IRMPD spectroscopy combines the advantages of MS and spectroscopy, as the mass and the IR fingerprint of mass selected ions are recorded simultaneously. Since the seminal paper of Ohanessian et al, ${ }^{15}$ IRMPD spectroscopy has become a key physical chemistry approach for the conformational analysis of biomolecules. However it has never been established as an hyphenated MS analytical tool despite its evident potential for the disambiguation of isomers. Following the pioneer work of John Simons on the gas phase IR spectroscopy of sugars ${ }^{16}$ and our earlier report of the first application of IRMPD for the disambiguation of isobaric sulfated and phosphated saccharides, ${ }^{17}$ we propose the first exploration of positional isomers of sulfated carbohydrates.

In the first section of this article, we report the structure of protonated glucosamine $3-\mathrm{S}$ and glucosamine 6-S, supported by theory, then we show that these species display diagnostic IRMPD signatures in their native state, i.e. deprotonated. In the second section, we aim at exploiting the analytical potential of a frugal IRMPD approach to discriminate sulfated isomers of two pairs of disaccharides of biological interest, namely heparan sulfate and chondroitin sulfate.

\section{RESULTS AND DISCUSSION}

\section{Spectroscopic diagnostic of positional isomers of sulfated monosaccharides}

As a proof of principle of the resolving power of IRMPD spectroscopy, we present the diagnostic signatures of glucosamine 3-S and 6-S in their protonated charge state; followed by a generic IRMPD analysis, that is a full conformational investigation supported by quantum chemistry.

The IRMPD signatures of the pair of isomers glucosamine 6-sulfate and 3-sulfate measured at the free electron laser facility FELIX $\left(800-1700 \mathrm{~cm}^{-1}\right)$ and using a tabletop IR system $\left(2700-3700 \mathrm{~cm}^{-1}\right)$ are reported in Figure 1. They are clearly distinct in both the long and short wavelength spectral ranges and allow for facile differentiation between the two isomers. To further exploit these IRMPD patterns in terms of molecular conformation and to assign spectral features to specific molecular vibration, a thorough conformational search followed by DFT simulation of the frequencies at the CAMB3LYP/6-311++G(2df,2pd) level was carried out. Around 200 conformers were obtained for each anomer of glucosamine 3-sulfate, including 19 conformers of the $\alpha$ anomer and 17 conformers of $\beta$ anomer below $25 \mathrm{~kJ} / \mathrm{mol}$. These are further classified in three types of stable ring conformations: ${ }^{4} C_{1}$ chair, ${ }^{1} S_{3}$ skew and ${ }^{1} C_{4}$ chair. These conformations are characterized by a $\mathrm{H}$-bond between one of the protons of the amine group and one oxygen atom of the sulfate moiety. For both anomers, the lowest energy structure is a ${ }^{4} \mathrm{C}_{1}$ chair stabilized by a $\mathrm{H}$-bond between $\mathrm{OH}(4)$ and $\mathrm{OH}(6)$. Other ${ }^{4} \mathrm{C}_{1}$ chairs are observed at higher energies with small variations in $\mathrm{OH}$ interactions. The ${ }^{1} \mathrm{~S}_{3}$ conformation stabilized by a H-bond between $\mathrm{OH}(1)$ and $\mathrm{OH}(6)$ is only present for the $\beta$ anomer, and the third ring conformation, the ${ }^{1} \mathrm{C}_{4}$ chair, does not show any $\mathrm{OH}$ interactions for the $\alpha$ anomer; the $\beta$ anomer in this conformation lies at relative energies higher than $25 \mathrm{~kJ} / \mathrm{mol}$. The vibrational spectra for these conformations are then computed in the harmonic approximation and compared to the experimental spectrum in Figure SIl. The best match is obtained for a combination of the two anomeric configurations of the lowest energy conformation: a ${ }^{4} C_{1}$ chair. The conformational analysis of glucosamine 6-sulfate was previousy reported. ${ }^{18,19}$ It was found that it adopts the same ${ }^{4} C_{1}$ chair ring conformation. The differences between the two IRMPD spectra thus originate solely from the different positions of the sulfate group and the induced differences in intra-molecular hydrogen bonding.

Once the stable conformation is established, the spectra can be interpreted in terms of molecular vibration: the carbohydrate $\mathrm{OH}$ stretches between 3500 and $3680 \mathrm{~cm}^{-1}$, a distinctive $\mathrm{NH}_{3}{ }^{+}$pattern between 3100 and $3400 \mathrm{~cm}^{-1}$ and four diagnostic modes of the neutral sulfate moiety: the $(\mathrm{S}) \mathrm{OH}$ stretch, the asymmetric $\mathrm{SO}_{2}$ stretch, the symmetric $\mathrm{SO}_{2}$ stretch and the $\mathrm{SO}(\mathrm{H})$ stretch, which range from 800 to $3600 \mathrm{~cm}^{-1}$. Their experimental frequencies are reported in Figure 1 and diagnostic bands are highlighted in contrasting color. In the FEL region, the pattern of sulfate vibrational bands appears as a distinctive diagnostic of the positional isomers, with frequency shifts ranging from -47 to +21 between protonated glucosamine 3 -sulfate and 6-sulfate. In the high energy range, indirectly, the pattern of carbohydrate $\mathrm{OH}$ stretching bands is also a straightforward signature of the sulfate position: the functionalization of $\mathrm{O}_{3}$ and $\mathrm{O}_{6}$ results in the disappearance of the $\mathrm{OH}(3)$ stretch at 3600 $\mathrm{cm}^{-1}$ and the $\mathrm{OH}(6)$ stretch at $3666 \mathrm{~cm}^{-1}$, respectively (a detailed mode analysis is shown in Figures $\mathrm{SI}_{2}$ and $\mathrm{SI}_{3}$ of the Supporting Information). 


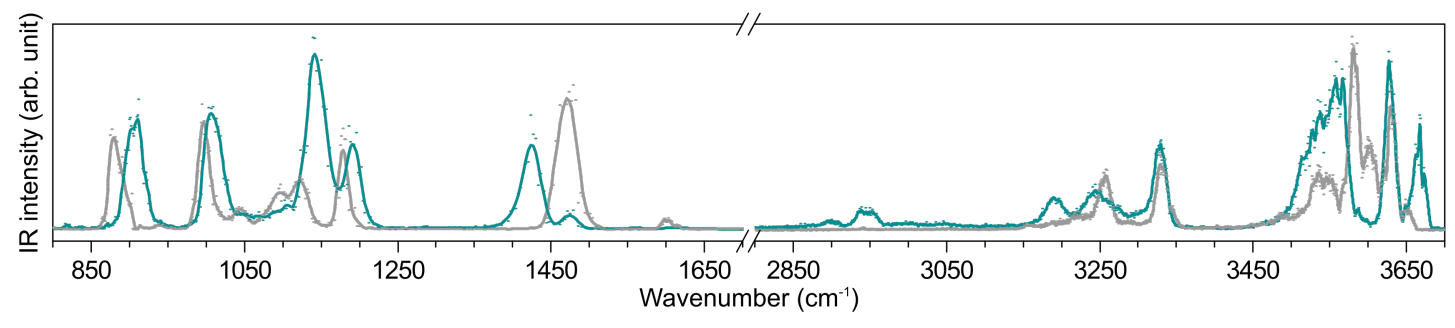

\begin{tabular}{|c|c|c|}
\hline Exp. frequencies $\left(\mathrm{cm}^{-1}\right)$ & glucosamine 3-sulfate & glucosamine 6-sulfate \\
\hline \multicolumn{3}{|l|}{ Carbohydrate $\mathrm{OH}$ stretches } \\
\hline $\mathrm{OH}(1)$ & 3628 & 3630 \\
\hline $\mathrm{OH}(3)$ & $x$ & 3600 \\
\hline $\mathrm{OH}(4)$ & 3545 (broad) & 3550 \\
\hline $\mathrm{OH}(6)$ & 3666 & $x$ \\
\hline \multicolumn{3}{|l|}{ Neutral sulfate moiety } \\
\hline (S)OH stretch & 3545 (broad) & 3595 \\
\hline asym. SO2 stretch & 1425 & 1472 \\
\hline sym. SO2 stretch & 1190 & 1180 \\
\hline $\mathrm{SO}(\mathrm{H})$ stretch & 906 & 885 \\
\hline \multicolumn{3}{|l|}{ Protonated amino group } \\
\hline high energy sym. stretch & 3328 & 3330 \\
\hline low energy sym.stretch & $3247(\beta)$ & 3250 \\
\hline
\end{tabular}

Figure 1: IRMPD spectra of protonated glucosamine 6-sulfate (grey: $\left.[\mathrm{GlcN} 6 \mathrm{~S}+\mathrm{H}]^{+}\right)$and 3-sulfate $\left(\mathrm{cyan}:[\mathrm{GlcN} 3 \mathrm{~S}+\mathrm{H}]^{+}\right)$in the $800-1700 \mathrm{~cm}^{-1}$ and $2800-3700 \mathrm{~cm}^{-1}$ spectral ranges and table of experimental IR frequencies for protonated glucosamine 3-sulfate and 6-sulfate.

Sulfated biomolecules however, are generally deprotonated in their native state. Although IRMPD spectroscopy of deprotonated ions can be done using the high fluence available at free electron laser facilities, ${ }^{19^{-22}}$ it is notoriously difficult to achieve with a tabletop IR system. ${ }^{23-25}$ This is regarded as a major limitation of the IRMPD technique and constitute a severe obstacle to its rise as a routine analytical tool. The performance of our IRMPD setup were enhanced by tignthening the focus of the laser beam ( $15 \mathrm{~cm}$ focus). This allowed to overcome this limitation and to perform systematic analysis of deprotonated ions, not only using a FEL, but also using a compact setup.

Surprisingly, the FEL spectral range does not appear particularly informative in this study. Indeed, the spectrum of deprotonated glucosamine 6-sulfate in the $800-1700 \mathrm{~cm}^{-1}$ spectral range shown in Figure 2 is remarkably similar to this of other deprotonated sulfated compounds such as fucose 3-sulfate (shown in Fig. 2) or even sulfoserine (from ref ${ }^{25}$ ) They essentially display two doublets of bands, one centered around $1025 \mathrm{~cm}^{-1}$ and the other around $1250 \mathrm{~cm}^{-1}$. Hence, the infrared signature in the $800-1700 \mathrm{~cm}^{-1}$ spectral range does not offer a clear signature of sulfated compounds. A theoretical exploration of the IRMPD signature of anionic sulfated compounds in the FEL range is shown in Fig. SI4. It reveals that these features correspond to the a pattern of sulfate modes, which is poorly isomer or conformer dependent.

In contrast, the spectra of anionic glucosamine 6sulfate and 3 -sulfate recorded in the $2700-3700 \mathrm{~cm}^{-1}$ spectral range, displayed in figure 2 (rignt panel), show a number of distinctive features. In the $\mathrm{OH}$ stretching range, resolved features are observed at 3576 and 3495 $\mathrm{cm}^{-1}$, for glucosamine 6-sulfate and 3-sulfate, respectively. A broad active region corresponding to unresolved $\mathrm{H}$ bonded $\mathrm{OH}$ stretch bands is observed with maximal absorption at 3200 and $3305 \mathrm{~cm}^{-1}$, respectively, likely convoluted with $\mathrm{NH}_{2}$ stretch modes expected in the same region. The $\mathrm{CH}$ stretch patterns are both centered around $2900 \mathrm{~cm}^{-1}$. Thus, in absence of diagnostic in the low frequency range, the high frequency range offers an excellent alternative for the identification of the sulfate position. A conformational search followed by DFT simulation of the frequencies at the CAMB3LYP/6$311++\mathrm{G}(2 \mathrm{df}, 2 \mathrm{pd})$ level was carried out. The calculated spectrum obtained for the lowest energy conformer og GlcN6S, a ${ }^{4} C_{1}$ chair, is shown in $\mathrm{SI}_{5}\left(\mathrm{GlcN}_{3} \mathrm{~S}\right.$ in SI6). The main groups of features, namely the free and/or weakly $\mathrm{H}$-bonded $\mathrm{OH}$ groups $\left(\mathrm{OH}_{1}\right.$ and $\left.\mathrm{OH}_{3}\right)$ at high energy, the $\mathrm{NH}$ modes around $3400 \mathrm{~cm}^{-1}$, and the strongly $\mathrm{H}$-bonded $\mathrm{OH}_{4}$ group around $3200 \mathrm{~cm}^{-1}$ reasonably match the main features observed in the experimental spectrum. It is noteworthy, however, that based on our experience of IRMPD spectroscopy of positively charged species, these spectra of anionic species are very atypical. Indeed only four $\mathrm{OH}$ modes and two $\mathrm{NH}$ modes are responsible for the broad feature between 3000 and $3600 \mathrm{~cm}^{-1}$ and it is very surprising that they are not better resolved. Further studies of anionic species in this spectral range will be essential to build new chemical intuition and better interpret these atypical patterns. 

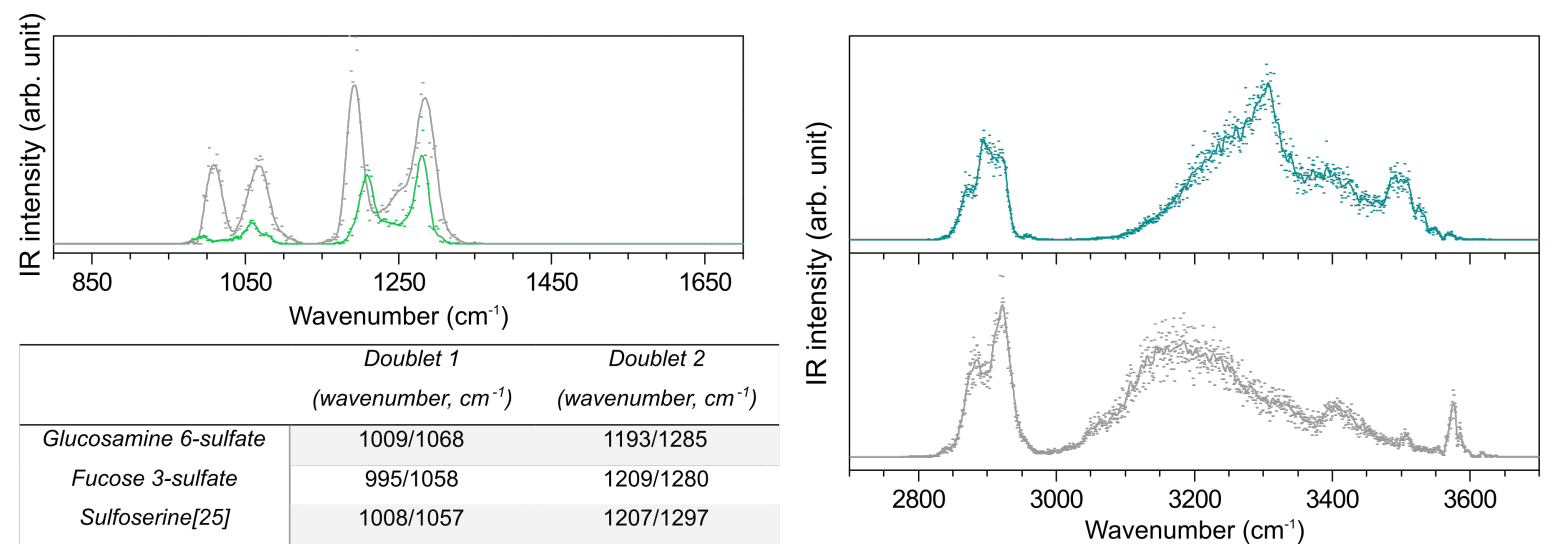

Figure 2. Left: IRMPD spectra of deprotonated glucosamine 6-sulfate (grey: [GlcN6S - H] $]^{-}$) and fucose 3-sulfate (green: [Fuc3S $\mathrm{H}]^{-}$) in the $800-1700 \mathrm{~cm}^{-1}$ spectral range. Table of IR frequencies observed in the $800-1700 \mathrm{~cm}^{-1}$ spectral range. Right: IRMPD spectra of deprotonated glucosamine 6-sulfate (grey: [GlcN6S - H] $]^{-}$) and glucosamine 3-sulfate (cyan: $\left[\mathrm{GlcN}_{3} \mathrm{~S}-\mathrm{H}^{-}\right.$) in the $2700-$ $3700 \mathrm{~cm}^{-1}$ spectral range.

Application to the analysis of sulfate patterns in glycosaminoglycan fragments

The high sensitivity of IRMPD spectroscopy for distinguishing positional isomers of sulfated monosaccharides appears promising for studying more complex sulfated carbohydrates like GAGs. They are expressed at the surface of mammalian cells and in the extracellular matrix (e.g. heparan sulfate (HS) and chondroitin sulfate (CS)) and are involved in a wide range of biological processes such as signaling, ${ }^{26}$ development, ${ }^{27}$ inflammation, ${ }^{28}$ cancer, ${ }^{29,30}$ and coagulation. ${ }^{31}$ One of the key questions in the understanding of the biological activity of GAGs is the identification of the sulfate position. They appear naturally as deprotonated biomolecules, therefore, the capacity of our technic to record IRMPD spectra of deprotonated species is particularly relevant. Four GAG-derived isomeric $\Delta$ unsaturated monosulfated disaccharide are compared in this study and shown in the scheme in fig. 3: two derived from heparin $\triangle \mathrm{UA}(2 S)-[1 \rightarrow 4]-G I c N A c(1, \mathrm{Hp}$ III-A) and $\Delta \mathrm{UA}-[1 \rightarrow 4]-\mathrm{GlcNAc}(6 S) \quad(2, \mathrm{Hp}$ II-A) and two derived from chondroitin sulfate $\Delta \mathrm{UA}-[1 \rightarrow 3]-$ GalNAc- $4 \mathrm{~S}(3, \mathrm{CS}-\mathrm{A})$ and $\Delta \mathrm{UA}-[1 \rightarrow 3]-$ GalNAc-6S $(4, \mathrm{CS}-\mathrm{C})$.

The two heparin monosulfated disaccharides Hp II-A and Hp III-A are characterized by sulfation on the $\mathrm{N}$ acetyl glucosamine or on the unsaturated uronic acid, respectively. Their IRMPD spectra in the negative ion mode between $550-1850 \mathrm{~cm}^{-1}$ and $2700-3700 \mathrm{~cm}^{-1}$ are shown in Figure 3.

In the low frequency range, both spectra display quite distinct patterns in contrast to the monosaccharides discussed above. The IRMPD spectrum of Hp II-A displays three of the deprotonated sulfate specific modes observed also in the spectra of the monosaccharides: at 1280 (free $\mathrm{S}=\mathrm{O}$ stretch), 1180 (H-bonded $\mathrm{S}=\mathrm{O}$ stretch) and $1030 \mathrm{~cm}^{-1}$ ( $\left.\mathrm{SO}_{3} \mathrm{sym}\right)$. The intense $\mathrm{C}-\mathrm{O}$ stretch observed around $1060 \mathrm{~cm}^{-1}$ in monosaccharides is not observed here. For the IRMPD spectrum of Hp III-A, the pattern is different from the sulfated monosaccharide reference. The band at $1033 \mathrm{~cm}^{-1}$ is similar to that in the spectrum of Hp II-A, but the bands at $1323 \mathrm{~cm}^{-1}$ and $1230 \mathrm{~cm}^{-1}$ are shifted to higher frequencies by $50 \mathrm{~cm}^{-1}$.

For both isomers, the absence of the characteristic neutral sulfate modes around 900 and $1450 \mathrm{~cm}^{-1}$, indicates deprotonation of the sulfate group, in agreement with chemical intuition. Additionally carboxylate function would show a diagnostic mode near $1630 \mathrm{~cm}^{-1} 3^{2}$ which is not observed here. This confirms the deprotonation of the sulfate group.

In the high frequency range, IRMPD spectra of Hp II-A and Hp III-A display the typical features of negatively charged sulfated saccharides as established above for sulfated monosaccharides, that is: a $\mathrm{CH}$-stretch absorption pattern around $2900 \mathrm{~cm}^{-1}$, and a broad and unresolved region at higher energy. They also display two partially resolved bands at 3510 and $3586 \mathrm{~cm}^{-1}$. The overall shape is distinctive of the isomer: Hp III-A shows a dominant feature between 3300 and $3500 \mathrm{~cm}^{-1}$ and a single feature at $2940 \mathrm{~cm}^{-1}$. In contrast, Hp II-A shows a broad active region between 3100 and $3500 \mathrm{~cm}^{-1}$ and two $\mathrm{C}-\mathrm{H}$ features at 2916 and $2944 \mathrm{~cm}^{-1}$. IR activity at 2915 and $3200 \mathrm{~cm}^{-1}$ is thus specific of Hp II-A.

The IRMPD signatures in the low and the high frequency range appear diagnostic of the sulfate position in these oligosaccharides.

The case of unsaturated disaccharides derived from chondroitin sulfate is a more difficult challenge as they possess two very close sites of sulfation on the $\mathrm{N}$-acetyl galactosamine that is $\mathrm{O} 6$ and $\mathrm{O}_{4}$. These two disaccharides derived from CS possess notoriously ambiguous MS/MS signatures with variable ratios of $\mathrm{Z}$ and $\mathrm{Y}$ ions depending on the experimental conditions, ${ }^{33-35}$ it is hence challenging to identify them by MS/MS.

Samples of CS-A and CS-C are studied and their IRMPD spectra in the high frequency range are shown in Figure 3. They display a similar pattern over the whole range, with 
$\mathrm{CH}$ features around $2930 \mathrm{~cm}^{-1}$ and a broad unresolved active region between 3100 and $3550 \mathrm{~cm}^{-1}$.
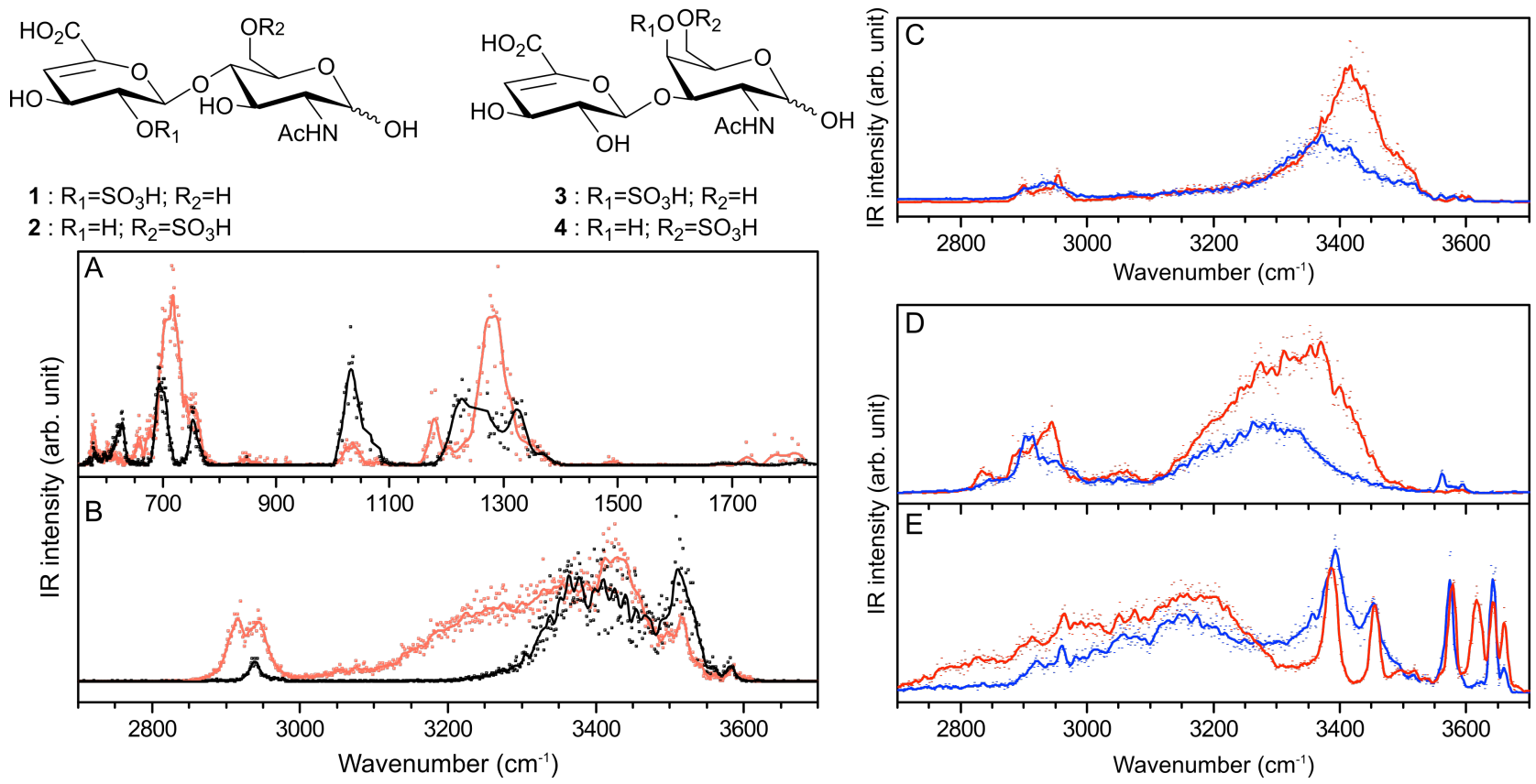

Figure 3. Scheme: $\Delta$-unsaturated disaccharides derived from HS (left) and CS (right). A\&B: IRMPD spectra of deprotonated Hp II-A (red: [Hp II-A - H] $]^{-}$) and Hp III-A (black: [Hp III-A - H] $]^{-}$) in the $550-1850 \mathrm{~cm}^{-1}$ and the $2700-3700 \mathrm{~cm}^{-1}$ spectral ranges. Right panels: IRMPD spectra of CS-A (red) and CS-C (blue) in different charge states. C: singly deprotonated [CS-A - H] and [CS-C $\mathrm{H}]^{-}$. D: doubly deprotonated $[\mathrm{CS}-\mathrm{A}-2 \mathrm{H}]^{2-}$ and $[\mathrm{CS}-\mathrm{C}-2 \mathrm{H}]^{2-}$. E: $\mathrm{NH}_{4}+$ cationic complexes $\left[\mathrm{CS}-\mathrm{A}+\mathrm{NH}_{4}\right]^{+}$and $\left[\mathrm{CS}-\mathrm{C}-\mathrm{NH}_{4}\right]^{+}$

Nonetheless, the IRMPD spectrum of CS-A shows two bands in the $\mathrm{CH}$ region at 2954 and $2902 \mathrm{~cm}^{-1}$ and a broad active region with a maximum absorption at $3405 \mathrm{~cm}^{-1}$ $\left(\mathrm{HWHM}=218 \mathrm{~cm}^{-1}\right)$, whereas the IRMPD signature of the CS-C displays a unique band in the $\mathrm{CH}$ region around $2930 \mathrm{~cm}^{-1}$ and a maximum absorption at $3370 \mathrm{~cm}^{-1}$ $\left(\mathrm{HWHM}=140 \mathrm{~cm}^{-1}\right)$ in the broad unresolved active region.

Additionally, the IRMPD spectra of unsaturated disaccharides derived from $\mathrm{Hp}$ are distinct from their isomers derived from CS. Hp show more structure with a partially resolved band at $3510 \mathrm{~cm}^{-1}$ which is not present for CSs. This exploration of GAG fragments is thus promising for GAG structural analysis. The mid-IR spectral range accessible with FELs offers a wealth of diagnostic features for Hp II-A and Hp III-A, but requires the FEL infrastructure which makes it impraticable for routine analysis. Instead, the high-energy range accessible with a table top laser system offers a relevant alternative for routine analysis: Using a compact IRMPD setup, we have been able to discriminate two $\mathrm{Hp}$ and two CS isomeric fragments.

The IRMPD signatures of CS fragments discussed above were recorded in their natural charge state. For analytical perspectives, it might be interesting to explore the spectroscopic resolving power of other charge states and counter ions accessible in MS. As an example doubly deprotonated and $\mathrm{NH}_{4}^{+}$adduct are shown in fig 3. Both spectra of doubly deprotonated species display similar features with a $\mathrm{CH}$ stretching region between 2800 and $3000 \mathrm{~cm}^{-1}$ and a broad active region in the $3100-3500 \mathrm{~cm}^{-1}$ spectral range. Nonetheless the IRMPD spectrum of doubly deprotonated CS-C shows a specific absorption band at $3562 \mathrm{~cm}^{-1}$. In the case of $\mathrm{NH}_{4}^{+}$adduct, the two IRMPD spectra show more structure: a large unresolved region between 2800 and $3320 \mathrm{~cm}^{-1}$ and two resolved bands observed at 3388 and $3455 \mathrm{~cm}^{-1}$. Remarkably the $\mathrm{OH}$ stretching range becomes highly diagnostic: the IRMPD spectrum of CS-A display four intense bands at $3576,3618,3642$ and $3660 \mathrm{~cm}^{-1}$ whereas in the IRMPD spectrum of CS-C, only two intense bands are observed at $3574,3641 \mathrm{~cm}^{-1}$. 


\section{CONCLUSION}

We have used a combination of gas phase IRMPD spectroscopy with mass spectrometry to address the differentiation of positional isomers of sulfated carbohydrates on monosaccharide standards and GAG disaccharides. The structure of protonated glucosamine 3sulfate and glucosamine 6-sulfate could both be assigned to a ${ }^{4} C_{1}$ chair conformation using DFT calculations. DFT simulation demonstrates that the features of the IRMPD spectrum clearly depend on the sulfate position. Differentiation of the biologically more relevant deprotonated compounds is more challenging as compared to protonated compounds. Indeed, we showed that the IRMPD signature of sulfated sugars in the FEL region is ambiguous and glucosamine 3-sulfate and glucosamine 6-sulfate could only be resolved in the OPO region. Moreover the DFT simulation of the IR spectrum of deprotonated carbohydrates appears as a new challenge for theoretical modelling.

Our exploration of anionic GAG fragments validates the potential of the spectroscopic approach to resolve isomeric disaccharides derived from the two GAG polysaccharides heparin and chondroitin sulfate. We have demonstrated that the resolving power of the spectroscopic signature can be enhanced by tuning the charge state of the analyte. The added value of the spectroscopic approach will be particularly useful when other MS-based analytical methods fail to resolve isomeric structures.

\section{METHODS}

\section{Samples}

Samples of glucosamine 6-sulfate and 3-sulfate were obtained from Sigma Aldrich. Fucose 3-sulfate was from Grampian Enzymes (UK), heparin disaccharides Hp II-A and Hp III-A were purchased from Dextra Laboratories (UK) and and chondroitin sulfate disaccharides CS-A and $\mathrm{CS}-\mathrm{C}$ were obtained from Iduron (UK).

\section{MS and IRMPD experiments}

Solutions were prepared for mass spectrometry at a concentration of $250 \mu \mathrm{M}$ in water/methanol solution (1:1). $0.1 \%$ of acetic acid was added to optimize ion signal in direct infusion.

IRMPD spectra of mass-selected ions were obtained using a modified ion trap mass spectrometer with an electrospray source from Thermo Finnigan (LCQ classic). Modifications allow the injection of a focused laser beam into the mass analyzer in order to irradiate the ion cloud, as described in our previous paper. ${ }^{17}$ An IRMPD spectroscopic scheme is used (InfraRed Multiple Photon Dissociation). IRMPD spectra were measured in two different regions, the $3 \mu \mathrm{m}$ region $\left(2700-3700 \mathrm{~cm}^{-1}\right)$ with a YAG-pumped tunable IR optical parametric oscillator/amplifier(OPO/A) (LaserVision) and the fingerprint region $\left(550-1850 \mathrm{~cm}^{-1}\right)$ with the beamline of the Free Electron Laser for Infrared eXperiments
(FELIX). ${ }^{36}$ Mass-selected ions were fragmented upon resonant IR excitation and the photofragmentation yield was plotted as a function of the wavenumber to obtain IRMPD spectra. Each experiment was performed at a repetition rate of $10 \mathrm{~Hz}$ and averaged 3 times with typical irradiation times of $400 \mathrm{~ms}$ and $700 \mathrm{~ms}$ for FELIX and OPO experiments, respectively.

\section{Theoretical methods}

A conformational search was achieved using $\mathrm{PM}_{7}{ }^{37}$ in the same way as in our previous paper, ${ }^{17}$ and optimization of the geometries and harmonic frequencies were computed using Gaussiano9. ${ }^{38}$ Density Functional Theory at the $\mathrm{CAMB}_{3} \mathrm{LYP}^{39}$ level of theory with the 6$311++\mathrm{G}(2 \mathrm{df}, 2 \mathrm{pd})^{40,41}$ basis set was chosen to take in account the difficulties to simulate vibrational spectra of sulfated species. ${ }^{18}$

The mode analysis was performed using Gabedit ${ }^{42}$ and an empirical scaling factor of 0.947 was used to correct the frequency of stretching modes in the $2700-3700 \mathrm{~cm}^{-1}$ spectral range.

\section{ASSOCIATED CONTENT}

NMR experiments.

Comparison of IRMPD spectra with theoretical IR spectra. This material is available free of charge via the Internet at http://pubs.acs.org.

\section{AUTHOR INFORMATION}

\section{Corresponding Author \\ * isabelle.compagnon@univ-lyonı.fr}

\section{ACKNOWLEDGMENT}

This work was supported by the LABEX iMUST (ANR-10LABX-oo64) of Université de Lyon, within the program "Investissements d'Avenir" (ANR-11-IDEX-0oo7) operated by the French National Research Agency (ANR). Experiments in the mid-IR region were performed at the free electron laser facility FELIX in Netherlands with the skillful assistance of the FELIX staff, in particular Dr Britta Redlich and Lex van der Meer. Travel costs to the Netherlands were supported by the Dutch-French Van Gogh program. In this work, we were granted access to the HPC resources of the FLMSN, "Féderation Lyonnaise de Modélisation et Sciences Numeriques", partner of EQUIPEX EQUIP@MESO and the HPC Resources from GENCI-CINES (Grant 2013-2014[087025]).

\section{REFERENCES}

(1) Hart, G. W.; Copeland, R. J. Glycomics Hits the Big Time. Cell 2010, 143 (5), 672-676.

(2) Cummings, R. D.; Pierce, J. M. The Challenge and Promise of Glycomics. Chem. Biol. 2014, 21 (1), 1-15.

(3) Kreuger, J. Interactions between Heparan Sulfate and Proteins: The Concept of Specificity. J. Cell Biol. 2oo6, 174 (3), 323-327.

(4) Lindahl, U.; Bäckström, G.; Thunberg, L.; Leder, I. G. Evidence for a 3-O-Sulfated D-Glucosamine Residue in the Antithrombin-Binding Sequence of Heparin. Proc. Natl. Acad. Sci. 1980, 77 (11), 6551-6555. 
Sugaya, N.; Habuchi, H.; Nagai, N.; Ashikari-Hada, S.; Kimata, K. 6-O-Sulfation of Heparan Sulfate Differentially Regulates Various Fibroblast Growth FactorDependent Signalings in Culture. J. Biol. Chem. 20o8, 283 (16), 10366-10376.

(6) Vivès, R. R.; Seffouh, A.; Lortat-Jacob, H. Post-Synthetic Regulation of HS Structure: The Yin and Yang of the Sulfs in Cancer. Front. Oncol. 2014, 3.

(7) Staples, G. O.; Zaia, J. Analysis of Glycosaminoglycans Using Mass Spectrometry. Curr. PROTEOMICS 2011, 8 (4), 325-336.

Wuhrer, M. Glycomics Using Mass Spectrometry. Glycoconj. J. 2013, 30 (1), 11-22.

(9) Ortiz, D.; Enjalbert, Q.; MacAleese, L.; Dugourd, P.; Salpin, J.-Y. Effects of Calcium Complexation on Heparin-like Disaccharides. A Combined Theoretical, Tandem Mass Spectrometry and Ultraviolet Experiment: Calcium Complexation of Heparin-like Disaccharides. Rapid Commun. Mass Spectrom. 2015, 29 (12), 1135-1144.

(10) Williams, J. P.; Grabenauer, M.; Holland, R. J.; Carpenter, C. J.; Wormald, M. R.; Giles, K.; Harvey, D. J.; Bateman, R. H.; Scrivens, J. H.; Bowers, M. T. Characterization of Simple Isomeric Oligosaccharides and the Rapid Separation of Glycan Mixtures by Ion Mobility Mass Spectrometry. Int. J. Mass Spectrom. 2010, 298 (1-3), 119127.

(11) Harvey, D. J.; Scarff, C. A.; Crispin, M.; Scanlan, C. N.; Bonomelli, C.; Scrivens, J. H. MALDI-MS/MS with Traveling Wave Ion Mobility for the Structural Analysis of N-Linked Glycans. J. Am. Soc. Mass Spectrom. 2012, 23 (11), 1955-1966.

(12) Seo, Y.; Andaya, A.; Leary, J. A. Preparation, Separation, and Conformational Analysis of Differentially Sulfated Heparin Octasaccharide Isomers Using Ion Mobility Mass Spectrometry. Anal. Chem. 2012, 84 (5), 2416-2423.

(13) Leach, F. E.; Arungundram, S.; Al-Mafraji, K.; Venot, A.; Boons, G.-J.; Amster, I. J. Electron Detachment Dissociation of Synthetic Heparan Sulfate Glycosaminoglycan Tetrasaccharides Varying in Degree of Sulfation and Hexuronic Acid Stereochemistry. Int. J. Mass Spectrom. 2012, 330-332, 152-159.

(14) Kailemia, M. J.; Park, M.; Kaplan, D. A.; Venot, A.; Boons, G.-J.; Li, L.; Linhardt, R. J.; Amster, I. J. HighField Asymmetric-Waveform Ion Mobility Spectrometry and Electron Detachment Dissociation of Isobaric Mixtures of Glycosaminoglycans. J. Am. Soc. Mass Spectrom. 2014, 25 (2), 258-268.

(15) Kapota, C; Lemaire, J; Maitre, P; Ohanessian G. Vibrational signature of charge solvation vs salt bridge isomers of sodiated amino acids in the gas phase. J. Am. Chem. Soc. 2004, 126, 1836-1842.

(16) Talbot F.; Simons J. P. Sugars in the gas phase: the spectroscopy and structure of jet-cooled phenyl $\beta$-Dglucopyranoside, Phys. Chem. Chem. Phys., 2002, 4, 3562-3565.

(17) Schindler, B.; Joshi, J.; Allouche, A.-R.; Simon, D.; Chambert, S.; Brites, V.; Gaigeot, M.-P.; Compagnon, I. Distinguishing Isobaric Phosphated and Sulfated Carbohydrates by Coupling of Mass Spectrometry with Gas Phase Vibrational Spectroscopy. Phys. Chem. Chem. Phys. 2014, 16 (40), 22131-22138.

(18) Barnes, L.; Schindler, B.; Allouche, A.-R.; Simon, D.; Chambert, S.; Oomens, J.; Compagnon, I. Anharmonic Simulations of the Vibrational Spectrum of Sulfated
Compounds: Application to the Glycosaminoglycan Fragment Glucosamine 6-Sulfate. Phys Chem Chem Phys 2015, 17 (39), 25705-25713.

(19) Wight, C. A.; Beauchamp, J. L. Infrared Spectra of GasPhase Ions and Their Use in Elucidating Reaction Mechanisms. Identification of $\mathrm{C}_{7} \mathrm{H}_{7}$ - Structural Isomers by Multiphoton Electron Detachment Using a LowPower Infrared Laser. J. Am. Chem. Soc. 1981, 103 (21), 6499-6501.

(20) Steill, J. D.; Oomens, J. Gas-Phase Deprotonation of $P$ Hydroxybenzoic Acid Investigated by IR Spectroscopy: Solution-Phase Structure Is Retained upon ESI. J. Am. Chem. Soc. 2009, 131 (38), 13570-13571.

(21) Oomens, J.; Steill, J. D.; Redlich, B. Gas-Phase IR Spectroscopy of Deprotonated Amino Acids. J. Am. Chem. Soc. 2009, 131 (12), 4310-4319.

(22) Crestoni, M. E.; Chiavarino, B.; Steinmetz, V.; Fornarini, S. Communication: Vibrational Study of a Benzyl Carbanion: Deprotonated 2,4-Dinitrotoluene. J. Chem. Phys. 2012, 137 (18), 181101.

(23) Almasian, M.; Grzetic, J.; van Maurik, J.; Steill, J. D.; Berden, G.; Ingemann, S.; Buma, W. J.; Oomens, J. NonEquilibrium Isomer Distribution of the Gas-Phase Photoactive Yellow Protein Chromophore. J. Phys. Chem. Lett. 2012, 3 (16), 2259-2263.

(24) Schinle, F.; Jacob, C. R.; Wolk, A. B.; Greisch, J.-F.; Vonderach, M.; Weis, P.; Hampe, O.; Johnson, M. A.; Kappes, M. M. Ion Mobility Spectrometry, Infrared Dissociation Spectroscopy, and Ab Initio Computations toward Structural Characterization of the Deprotonated Leucine-Enkephalin Peptide Anion in the Gas Phase. J. Phys. Chem. A 2014, 118 (37), 8453-8463.

(25) Paciotti, R.; Coletti, C.; Re, N.; Scuderi, D.; Chiavarino, B.; Fornarini, S.; Crestoni, M. E. Serine O-Sulfation Probed by IRMPD Spectroscopy. Phys. Chem. Chem. Phys. 2015, 17 (39), 25891-25904.

(26) Couchman, J. R. Transmembrane Signaling Proteoglycans. Annu. Rev. Cell Dev. Biol. 2010, 26 (1), 89-114.

(27) Haltiwanger, R. S.; Lowe, J. B. Role Of Glycosylation In Development. Annu. Rev. Biochem. 2004, 73 (1), 491-537.

(28) Taylor, K. R.; Gallo, R. L. Glycosaminoglycans and Their Proteoglycans: Host-Associated Molecular Patterns for Initiation and Modulation of Inflammation. FASEB J. 2006, 20 (1), 9-22.

(29) Afratis, N.; Gialeli, C.; Nikitovic, D.; Tsegenidis, T.; Karousou, E.; Theocharis, A. D.; Pavão, M. S.; Tzanakakis, G. N.; Karamanos, N. K. Glycosaminoglycans: Key Players in Cancer Cell Biology and Treatment. FEBS J. 2012, 279 (7), 1177-1197.

(30) Yip, G. W.; Smollich, M.; Götte, M. Therapeutic Value of Glycosaminoglycans in Cancer. Mol. Cancer Ther. 2oo6, 5 (9), 2139-2148.

(31) Casu, B.; Guerrini, M.; Torri, G. Structural and Conformational Aspects of the Anticoagulant and Antithrombotic Activity of Heparin and Dermatan Sulfate. Curr. Pharm. Des. 2004, 10 (9), 939-950.

(32) Oomens, J.; Steill, J. D. Free Carboxylate Stretching Modes. J. Phys. Chem. A 2008, 112 (15), 3281-3283.

(33) Desaire, H.; Leary, J. A. Detection and Quantification of the Sulfated Disaccharides in Chondroitin Sulfate by Electrospray Tandem Mass Spectrometry. J. Am. Soc. Mass Spectrom. 200o, 11 (10), 916-920. 
(34) Zaia, J.; Costello, C. E. Compositional Analysis of Glycosaminoglycans by Electrospray Mass Spectrometry. Anal. Chem. 2001, 73 (2), 233-239.

(35) Flangea, C.; Serb, A. F.; Schiopu, C.; Tudor, S.; Sisu, E.; Seidler, D. G.; Zamfir, A. D. Discrimination of GalNAc $\left.{ }_{4} \mathrm{~S} / 6 \mathrm{~S}\right)$ Sulfation Sites in Chondroitin Sulfate Disaccharides by Chip-Based Nanoelectrospray Multistage Mass Spectrometry. Cent. Eur. J. Chem. 2009, 7 (4), 752-759.

(36) Oepts, D.; van der Meer, A. F. G.; van Amersfoort, P. W. The Free-Electron-Laser User Facility FELIX. Infrared Phys. Technol. 1995, 36 (1), 297-308.

(37) Stewart, J. J. P. Optimization of Parameters for Semiempirical Methods VI: More Modifications to the NDDO Approximations and Re-Optimization of Parameters. J. Mol. Model. 2013, 19 (1), 1-32.

(38) Frisch, M. J.; Trucks, G. W.; Schlegel, H. B.; Scuseria, G. E.; Robb, M. A.; Cheeseman, J. R.; Scalmani, G.; Barone, V.; Mennucci, B.; Petersson, G. A.; et al. Gaussian o9; Gaussian, Inc.: Wallingford, CT, USA, 2009.

(39) Yanai, T.; Tew, D. P.; Handy, N. C. A New Hybrid Exchange Correlation Functional Using the Coulomb Attenuating Method (CAM-B3LYP). Chem. Phys. Lett. 2004, 393 (1-3), 51-57.

(40) Hehre, W. J.; Ditchfield, R.; Pople, J. A. Self-Consistent Molecular Orbital Methods. XII. Further Extensions of Gaussian-Type Basis Sets for Use in Molecular Orbital Studies of Organic Molecules. J. Chem. Phys. 1972, 56 (5), 2257-2261.

(41) Krishnan, R.; Binkley, J. S.; Seeger, R.; Pople, J. A. Self Consistent Molecular Orbital Methods .20. Basis Set for Correlated Wave Functions. J. Chem. Phys. 1980, 72 (1), 650-654.

(42) Allouche, A.-R. Gabedit-A Graphical User Interface for Computational Chemistry Softwares. J. Comput. Chem. 2011, 32 (1), 174-182. 


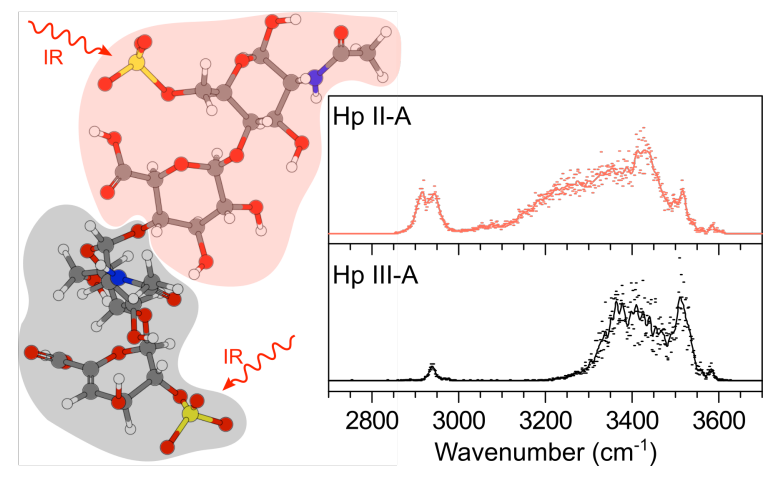

